\title{
Telmisartan inhibits the proinflammatory effects of homocysteine on human endothelial cells through activation of the peroxisome proliferator-activated receptor- $\delta$ pathway
}

\author{
SHANGHUA XU ${ }^{1 *}$, HUANHUAN SONG ${ }^{2 *}$, MAOZHI HUANG ${ }^{1}$, KEFENG WANG $^{3}$, \\ CHANGSHENG $\mathrm{XU}^{4}$ and LIANGDI XIE ${ }^{4}$ \\ ${ }^{1}$ Department of Cardiology, Nanping First Hospital Affiliated to Fujian Medical University, Nanping, \\ Fujian 353000; ${ }^{2}$ People's Hospital of Zhengzhou Yihe Hospital, Zhengzhou, Henan 450000; \\ ${ }^{3}$ Second Hospital Affiliated to Xi'an Medical School, Xi'an, Shaanxi 710000; \\ ${ }^{4}$ The Hypertension Institute of Fujian Province, Fuzhou, Fujian 350000, P.R. China
}

Received January 26, 2014; Accepted June 11, 2014

DOI: 10.3892/ijmm.2014.1834

\begin{abstract}
The aim of this study was to investigate the inhibition capacity of telmisartan to endothelial inflammation induced by homocysteine (Hcy) and discuss the proposed mechanism in vitro. Human umbilical vein endothelial cells (HUVECs) were prepared by collagenase digestion and cultured in vitro. An increase in monocyte chemoattractant protein-1 (MCP-1) and vascular cell adhesion molecule-1 (VCAM-1) was analyzed by reverse transcription-polymerase chain reaction (RT-PCR) as markers of Hcy-induced endothelial inflammation. HL-60 cell adhesion to HUVECs was measured by rose bengal staining. Nuclear, cytosolic and total nuclear transcription factor $-\kappa \mathrm{B}(\mathrm{NF}-\kappa \mathrm{B})$ p65 levels were analyzed by western blotting. Peroxisome proliferator-activated receptor- $\delta$ (PPAR $\delta$ ) expression by HUVECs exposed to Hcy with or without telmisartan pretreatment was analyzed by RT-PCR and western blotting. Hcy significantly increased the levels of MCP-1 mRNA, VCAM-1 mRNA and monocyte binding to HUVECs. These effects were significantly attenuated by pretreatment with telmisartan and PPARS agonists. The effect of telmisartan was inhibited by PPAR $\delta$ antagonists. The Hcy-mediated downregulation of PPAR $\delta$ mRNA and protein of HUVECs was inhibited by telmisartan. Hcy-mediated upregulation of $\mathrm{NF}-\kappa \mathrm{B}$ p65 protein levels in nuclear extracts was inhibited by telmisartan and PPAR $\delta$ agonists. In conclusion, telmisartan exerts potent anti-inflammatory effects in endothelial cells,
\end{abstract}

Correspondence to: Dr Shanghua Xu, Department of Cardiology, Nanping First Hospital Affiliated to Fujian Medical University, Nanping, Fujian 353000, P.R. China

E-mail: xshanghua@medmail.com.cn

${ }^{*}$ Contributed equally

Key words: telmisartan, peroxisome proliferator-activated receptor- $\delta$, inflammation, homocysteine, human umbilical vein endothelial cells probably via a binary mechanism involving PPAR $\delta$ activation and inhibition of the nuclear translocation of NF- $\mathrm{NB}$.

\section{Introduction}

Artery atherosclerosis is one of the most common causes of human morbidity and mortality, especially in industrialized societies. Increasing evidence suggests that atherosclerosis is a chronic inflammatory disease of the cardiovascular system and the inflammation related to endothelial cell dysfunction is a key step. Endothelial dysfunction is associated with the induction of adhesion molecules for inflammatory cells, such as intercellular cell adhesion molecule-1 (ICAM-1), vascular cell adhesion molecule-1 (VCAM-1), E-selectin and fibronectin (1-5).

Peroxisome proliferator-activated receptors (PPARs) are a family of nuclear receptors that have been identified and which function as heterodimers with 9-cis-retinoic receptor (RXR) by binding to a specific PPAR-responsive element in the promoter region of target genes. Three PPAR isoforms have been identified: PPAR $\alpha, \operatorname{PPAR} \gamma$ and PPAR $\delta$. Telmisartan is highly selective for the AII type 1 receptor and it is used for the treatment of hypertension. Recent studies suggest that telmisartan is also a functional PPAR $\gamma$ agonist and experimental evidence has indicated an association with decreased risk for atherosclerosis (6). Additionally, telmisartan influences the expression of PPAR $\gamma$ target genes involved in abdominal adiposity, dyslipidemia and insulin resistance $(7,8)$. A previous study also showed that telmisartan inhibits advanced glycation end-product (AGE)-induced endothelial cell injury by suppressing AGE receptor (RAGE) expression via PPAR $\gamma$ activation without side-effects suhc as thiazolidinedione (the PPAR $\gamma$ agonists) (9), including sodium and water retention. $(10,11)$. These observations indicate that telmisartan functions via an alternative pathway.

As one of the three PPAR isoforms, PPAR $\delta$ was reported to have non-metabolic functions involved in cell growth, wound healing and inflammation (12,13). Fernández-Fernández (14) found that long-term administration of angiotensin receptor blockers (ARB) significantly decreased visceral fat and 
prevented high-fat diet-induced obesity in wild-type mice and hypertensive rats but not in PPARd knockout mice. Furthermore, telmisartan, but not losartan or candesartan, increased PPAR $\delta$ expression in 3T3-L1 preadipocytes. However, no evidence has suggested that telmisartan exerts anti-inflammatory effects via the PPARd pathway. In this study, we investigated the effects of telmisartan on endothelial inflammation induced by homocysteine stimuli in cultured human umbilical vein endothelial cells (HUVECs) and discussed the proposed mechanism.

\section{Materials and methods}

HUVEC isolation and culture. Human umbilical vein endothelial cells (HUVECs) were isolated from full-term human umbilical cords $(15-20 \mathrm{~cm})$ obtained immediately post-partum by caesarean section from the first Affiliated Hospital of Fujian Medical University, and stored in M199 medium (Gibco, Gaithersburg, MD, USA). HUVECs were isolated by collagenase digestion of the sub-endothelial basement membrane. Briefly, the umbilical cord vein was cannulated and washed thoroughly using phosphate-buffered saline (PBS; Gibco) to remove blood cells. Sterile M199 medium containing $0.1 \%$ collagenase (type I, $10 \mathrm{ml}$ thawed at $37^{\circ} \mathrm{C}$ ) was infused into the umbilical vein and the other end of the umbilical cord was clamped with a hemostat. The umbilical cord was incubated for $10 \mathrm{~min}$ in a $37^{\circ} \mathrm{C}$ prior to the cell suspension being collected. Following centrifugation, the cells were resuspended in complete culture medium [M199 with 20\% FBS, $0.1 \mathrm{mM}$ L-glutamine, $20 \mu \mathrm{g} / \mathrm{ml}$ endothelial cell growth factor (ECGF), $50 \mu \mathrm{g} / \mathrm{ml}$ sodium heparin]. Cultures were maintained at $37^{\circ} \mathrm{C}$ in a humidified $\mathrm{CO}_{2}$ incubator and $2-4$ passages of HUVECs were used in the experiments.

Immunocytochemistry. HUVECs grown in chamber-slides were washed with PBS and fixed with $4 \%$ paraformaldehyde for $15 \mathrm{~min}$ at room temperature, then washed three times with PBS. Subsequently, the cells were exposed to $0.5 \%$ Triton X-100 in PBS for 20 min and washed three times with PBS. The cells were treated with $1 \%$ BSA in PBS for 3 min, incubated with specific primary antibody of rabbit anti-VWF (1:200; Dako, Glostrup, Denmark) at $4^{\circ} \mathrm{C}$ overnight. After washing, the cells were incubated with goat anti-rabbit IgG-R secondary antibody (1:400; Santa Cruz Biotechnology, Inc. Santa Cruz, CA, USA) for $30 \mathrm{~min}$ at room temperature. The specimens were observed under a fluorescence microscope (Olympus, Tokyo, Japan) (Fig. 1).

Experimental procedures and reagents. HUVECs, cultured in 6-well tissue culture plates, were preincubated with $1 \mu \mathrm{M}$ GW0742, $1 \mu \mathrm{M}$ GSK0660, $1 \mu \mathrm{M}$ telmisartan or $10 \mu \mathrm{M}$ PDTC for $30 \mathrm{~min}$ and then incubated with 1,000 $\mu \mathrm{M}$ Hcy (all from Sigma) for $24 \mathrm{~h}$.

RNA extraction and reverse transcription-polymerase chain reaction $(R T-P C R)$. A single-step method was used for the isolation of total RNA. Total RNA extraction was achieved using TRIzol reagent according to the manufacturer's instructions (Invitrogen Life Technologies, Grand Island, NY, USA). RNA yield was evaluated spectrophotometrically $\left(\mathrm{A}_{260} / \mathrm{A}_{280}\right)$.
For reverse transcription, $1 \mu \mathrm{g}$ RNA was incubated with $4 \mu \mathrm{l}$ PrimeScript buffer, $1 \mu$ l PrimeScript RT Enzyme Mix (Takara, Shiga, Japan), $1 \mu \mathrm{l}$ oligo(dT) primer, and $1 \mu \mathrm{l}$ random 6-mers. RNase-free $\mathrm{dH}_{2} \mathrm{O}$ was then added to produce a final volume of $20 \mu \mathrm{l}$. The reaction mixture was incubated at $37^{\circ} \mathrm{C}$ for $15 \mathrm{~min}$ and then at $85^{\circ} \mathrm{C}$ for $5 \mathrm{sec}$ to inactivate the enzyme (15).

Quantitative PCR was performed with $2 \mu \mathrm{l}$ DNA, $10 \mu \mathrm{l}$ SYBR Premix Ex Tag ${ }^{\text {TM }}$ (Takara), $0.4 \mu$ l forward primer, $0.4 \mu \mathrm{l}$ reverse primer, $0.4 \mu \mathrm{l}$ ROX Reference Dye. $\mathrm{dH}_{2} \mathrm{O}$ was then added to produce a final volume of $20 \mu \mathrm{l}$. The reaction was incubated for $30 \mathrm{sec}$ at $95^{\circ} \mathrm{C}$ followed by 40 cycles of $5 \mathrm{sec}$ at $95^{\circ} \mathrm{C}, 30 \mathrm{sec}$ at $60^{\circ} \mathrm{C}$ using the following primers for quantitative PCR: MCP-1, 5'-CTTCTGTGCCTGCTGCTCATA-3' and 5'-CTTTGGGACACTTGCTGCTG-3'; VCAM-1, 5'-CGA AAGGCCCAGTTGAAGGA-3' and 5'-GAGCACGAGAAG CTCAGGAGAAA-3'; PPARס, 5'-AAGGCATCGGGCTTC CACTA-3' and 5'-GCACTTCTGGAAGCGGCAGTA-3'; GAPDH, 5'-GCACCGTCAAGGCTGAGAAC-3' and 5'-TGG TGAAGACGCCAGTGGA-3'. The expression of mRNA levels was measured as the ratio of each mRNA to GAPDH mRNA.

Western blot analysis. Total protein was extracted from HUVECs with ice-cold lysis buffer as previously described (16). For the preparation of nuclear and cytosolic protein extracts, the cells were treated with $200 \mu \mathrm{l}$ pre-cooled buffer A (containing $1 \mu \mathrm{l}$ DTT, $10 \mu \mathrm{l}$ PMSF, $1 \mu$ l protease inhibitor per $\mathrm{ml}$ ) and vortexed for $15 \mathrm{sec}$. After incubation on ice for $15 \mathrm{~min}, 11 \mu \mathrm{l}$ pre-cooled buffer B was added, vortexed for $5 \mathrm{sec}$ and incubated on ice for $1 \mathrm{~min}$. Cytosolic proteins were obtained by centrifuging at $14,000 \mathrm{x} \mathrm{g}$ for $5 \mathrm{~min}$ at $4^{\circ} \mathrm{C}$. The pellets were resuspended in $100 \mu 1$ pre-cooled buffer $\mathrm{C}$ (containing $1 \mu \mathrm{l}$ DTT, $10 \mu \mathrm{l} \mathrm{PMSF}, 1 \mu \mathrm{l}$ protease inhibitor per $\mathrm{ml}$ ) and vortexed for $15 \mathrm{sec}$. Following incubation at $4^{\circ} \mathrm{C}$ for $40 \mathrm{~min}$, the samples were centrifuged at $14,000 \mathrm{x} \mathrm{g}$ for $5 \mathrm{~min}$ at $4^{\circ} \mathrm{C}$ to isolate the supernatant containing nuclear proteins. The samples $(20 \mu \mathrm{l})$ were loaded and subjected to SDS-PAGE (10\% gel). Proteins were electrotransferred to PVDF membranes prior to blocking in TBS-T (5\% non-fat dry milk in Tris-buffered saline with Tween-20 for $1 \mathrm{~h}$ at room temperature. The membrane was then incubated with primary antibody overnight at $4^{\circ} \mathrm{C}$.

Rabbit anti-nuclear factor- $\kappa \mathrm{B}(\mathrm{NF}-\kappa \mathrm{B})$ p65 antibody (1:2,000; Cell Signaling Technology, Beverly, MA, USA); rabbit anti-PPARd antibody (1:200; Abcam, Cambridge, UK); murine anti- $\beta$-actin polyclonal antibody $(1: 1,000)$ and rabbit anti-histone polyclonal antibody (1:200) (both from Santa Cruz Biotechnology, Inc.). Subsequently, the membrane was washed three times in TBS-T and incubated for $1 \mathrm{~h}$ at room temperature with horseradish peroxidase-conjugated secondary antibody of goat anti-rabbit IgG or goat anti-mouse IgG (1:2,000; Beijing Zhongshan Biotechnology, Beijing, China). Antigen detection was performed via the ECL reagent and exposed to film (Kodak, Xiamen, China).The band intensities were quantified using a scanning densitometer. $\beta$-actin expression was used as an internal standard for total and cytosolic protein, and histone expression was used as an internal standard for nuclear protein.

Adhesion assays. HUVECs were cultured in 96-well tissue culture plates and grown to confluence. The cells were then incubated with GW0742, GSK0660, telmisartan and Hcy for $20 \mathrm{~h}$. HL60 cells $\left(3 \times 10^{5}\right)$ were added to each well and incubated 

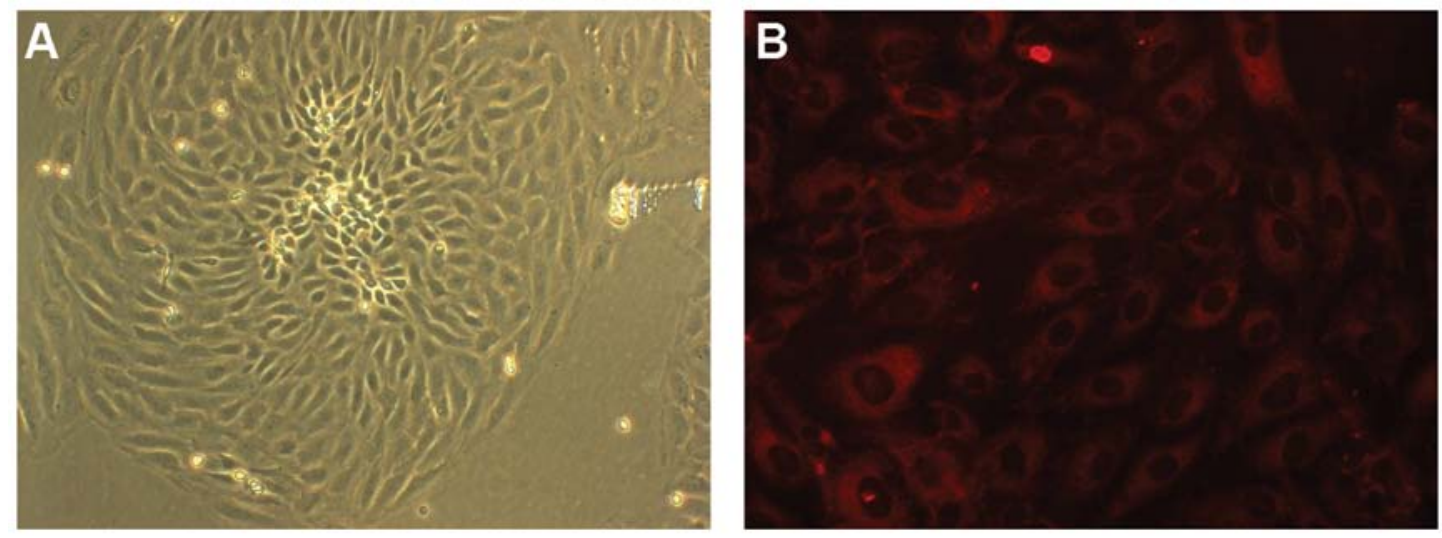

Figure 1. Immunohistochemisty of human umbilical vein endothelial cells (HUVECs). (A) The primary HUVECs were observed under the microscope, and the confluent cells showed presenting a 'pavement stones'. (B) The immunohistochemisty of von Willebrand factor (VWF) were observed under the fluorescence microscope, and red fluorescence was observed in the cytoplasm under the fluorescence microscope.

for $1 \mathrm{~h}$ at $37^{\circ} \mathrm{C}$. Non-adherent HL60 cells were removed by washing the wells three times with PBS. Adherence of HL60 cells to HUVECs was photographed under a phase-contrast microscope (Olympus). Rose Bengal (100 $\mu 1 ; 0.25 \%)$ stain was added to each well and incubated for $10 \mathrm{~min}$ at room temperature. PBS-ethanol (1:1) was added and incubated for $1 \mathrm{~h}$ at room temperature after washing the wells. Absorbance $(570 \mathrm{~nm})$ was measured using a microplate reader (Bio-Rad, Hercules, CA, USA).

Statistical analysis. Data were expressed as the mean \pm SEM. Two-way ANOVA was used for comparisons between the two groups. Data were analyzed using SPSS 18.0 and results were considered statistically significant at $\mathrm{P}<0.05$.

\section{Results}

Telmisartan attenuates the effect of the increased expression of MCP-1 and VCAM-1 in HUVECs caused by Hcy. Hcy significantly increased the mRNA expression of MCP-1 and VCAM-1 in a concentration-dependent manner (data not shown). Pretreatment with telmisartan significantly attenuated the Hcy-induced MCP-1 and VCAM-1 mRNA expression in a concentration-dependent manner (data not shown).

Effects of telmisartan, PPARS agonists and antagonists on Hcy-induced MCP-1 and VCAM-1 mRNA expression in HUVECs. The functional significance of the activation of the PPAR $\delta$ pathway by telmisartan was investigated. Hcy significantly increased the mRNA expression of MCP-1 and VCAM-1. Pretreatment with telmisartan and GW0742 significantly attenuated the Hcy-induced MCP-1 and VCAM-1 mRNA expression, while the effect of telmisartan was not inhibited by GSK0660 (Fig. 2).

Effects of telmisartan, PPAR agonists and antagonists on HUVEC adhesion molecules in vitro. The endothelial inflammation was investigated in Hcy-induced monocyte adhesion assays. HL-60 cell adhesion assays showed significantly increased monocyte binding to confluent HUVECs following

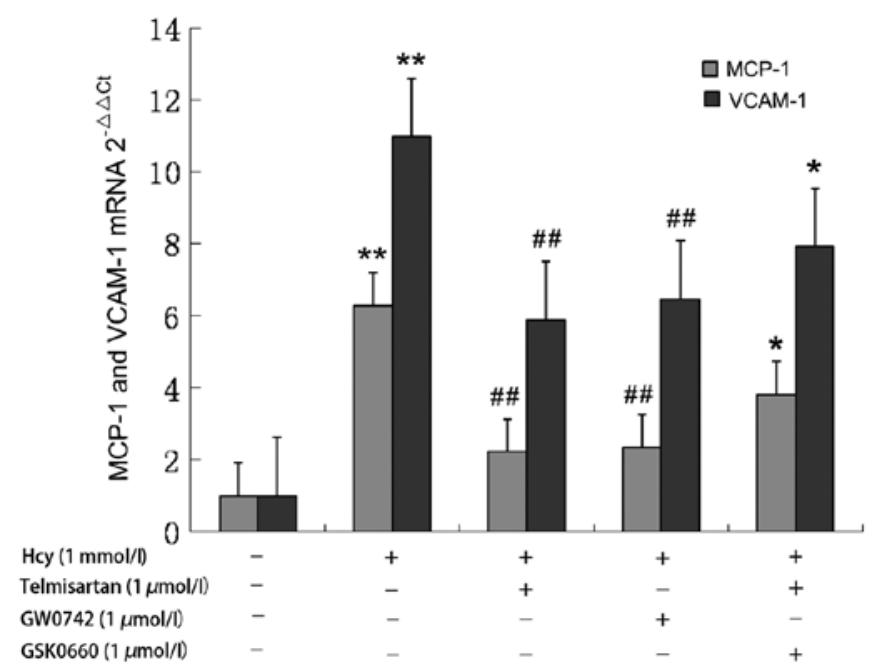

Figure 2. Effects of telmisartan, GW0742 [peroxisome proliferator-activated receptor- $\delta$ (PPAR $\delta$ ) agonist] and GSK0660 (PPAR $\delta$ antagonist) plus telmisartan treatment on homocysteine (Hcy) induced monocyte chemoattractant protein-1 (MCP-1) and vascular cell adhesion molecule-1 (VCAM-1) mRNA expression in human umbilical vein endothelial cells (HUVECs). Incubation with Hcy significantly increased the mRNA expression of MCP-1 and VCAM-1. Telmisartan and GW0742 significantly attenuated the effect of Hcy in HUVECs, while the effect of telmisartan was inhibited by GSK0660 $(\mathrm{n}=5) .{ }^{* *} \mathrm{P}<0.01$ vs. control group; \#\#P<0.01 vs. Hcy group; ${ }^{*} \mathrm{P}<0.05$ vs. telmisartan group.

Hcy incubation in a concentration-dependent manner (data not shown). Telmisartan and GW0742 significantly reduced the adherence to HUVECs, while the effects of telmisartan were inhibited by GSK0660 (Fig. 3).

Effects of telmisartan and PPAR agonists on PPARס. RT-PCR and western blot analysis of PPAR $\delta$ mRA and protein were performed to investigate the effect of telmisartan on PPAR $\delta$. Hcy significantly decreased the mRNA expression of PPAR $\delta$, while GW0742 and telmisartan significantly attenuated the effect of Hcy in HUVECs (Fig. 4). The protein expression of PPAR $\delta$ was also decreased by Hcy, while GW0742 and telmisartan significantly attenuated the effect of Hcy in HUVECs (Fig 5). 
A

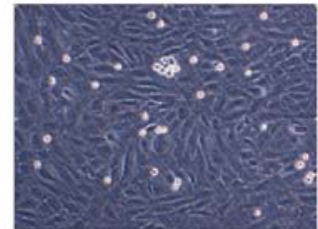

Control

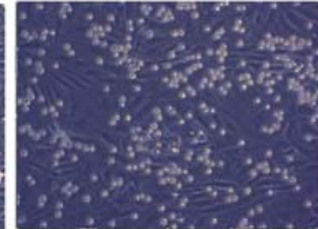

Hcy

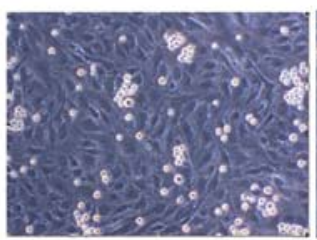

Telmisartan

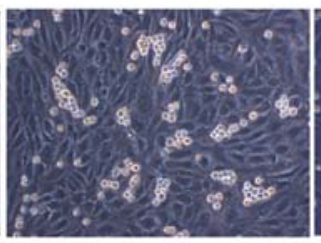

GW0742

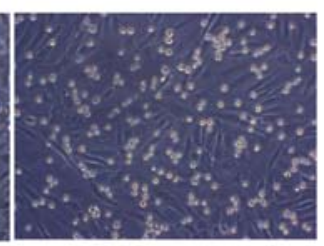

GSK0660

B

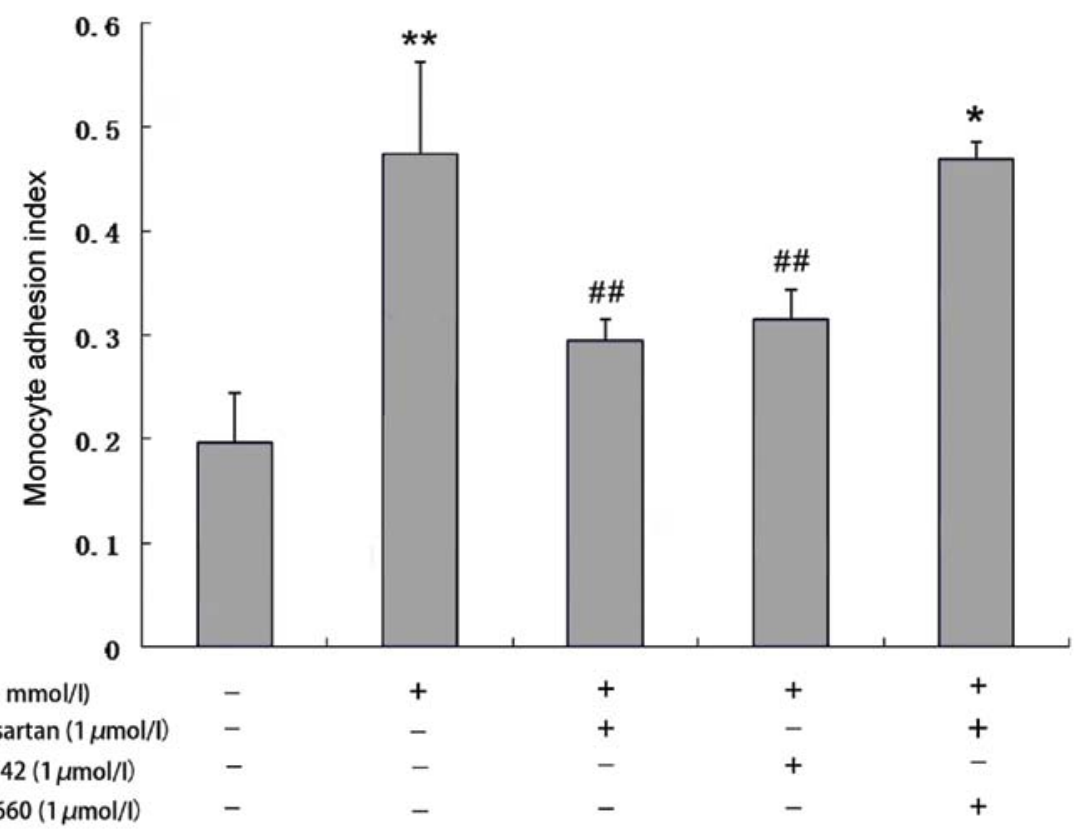

Figure 3. Effects of telmisartan, GW0742 [peroxisome proliferator-activated receptor- $\delta$ (PPAR $\delta$ ) agonist] and GSK0660 (PPAR $\delta$ antagonists) plus telmisartan treatment on homocysteine (Hcy)-induced adhesion molecules expressed by human umbilical vein endothelial cells (HUVECs) in vitro. (A) HL-60 cell adhesion assay showed significant increase of monocyte binding to confluent HUVECs after Hcy incubation. (B) Telmisartan and GW0742 significantly reduced the amount of adherence to HUVECs, while the effect of telmisartan was inhibited by GSK0660 ( $\mathrm{n}=3$ ). ${ }^{* *} \mathrm{P}<0.01 \mathrm{vs}$. control group; ${ }^{\# \#} \mathrm{P}<0.01$ vs. Hcy group; ${ }^{*} \mathrm{P}<0.05$ vs. telmisartan group.

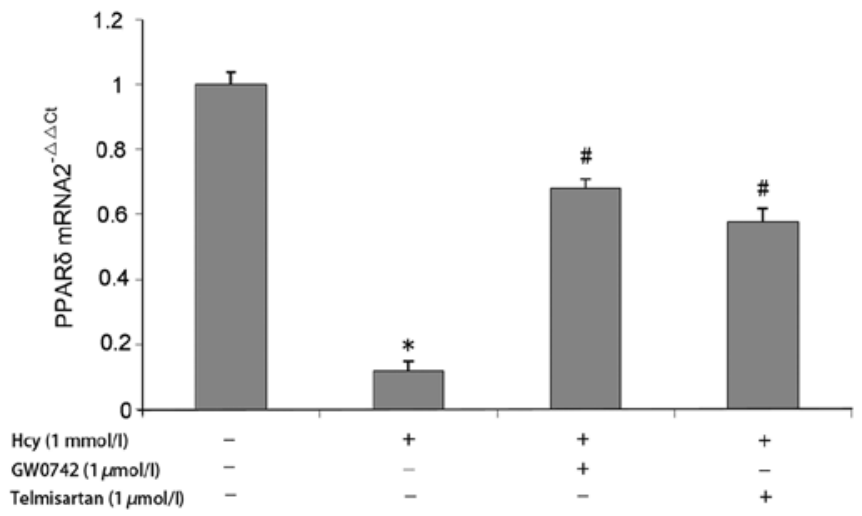

Figure 4. The effect of telmisartan on the expression of peroxisome proliferator-activated receptor- $\delta$ (PPAR $\delta$ ) mRNA. RT-PCR was used to analyze the relative gene expression of PPAR $\delta$ mRNA in human umbilical vein endothelial cells (HUVECs). Incubation with homocysteine (Hcy) significantly decreased PPARס expression. GW0742 and telmisartan significantly attenuated the effect of Hcy in HUVECs $(n=3) .{ }^{*} \mathrm{P}<0.05$ vs. control group; ${ }^{*} \mathrm{P}<0.05$ vs. Hcy group.
Effects of PPARD agonists and antagonists and $N F-\kappa B$ inhibitors on Hcy-induced $m R N A$ expression of MCP-1 and VCAM-1 in HUVECs. Hcy significantly increased the mRNA expression of MCP-1 and VCAM-1. Pretreatment

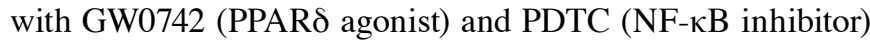
significantly attenuated the Hcy-induced MCP-1 and VCAM-1 mRNA expression, while GSK0660 (PPARס antagonist) had no effect (Fig. 6).

Effects of telmisartan, PPAR agonists and antagonists on Hcy-induced NF- $\kappa B$ p65 translocation in HUVECs. Hcy induced NF- $\kappa \mathrm{B}$ p65 protein expression in nuclear proteins. The functional significance of the inhibition of the NF- $\kappa B$ p65 pathway activation by GW0742 was investigated by western blot analysis of NF- $\mathrm{B}$ p65 levels in total, nuclear and cytosolic proteins. Treatment with GW0742 and telmisartan significantly attenuated NF-kB p65 translocation in HUVECs, while GSK0660 had no effect (Fig. 7). 


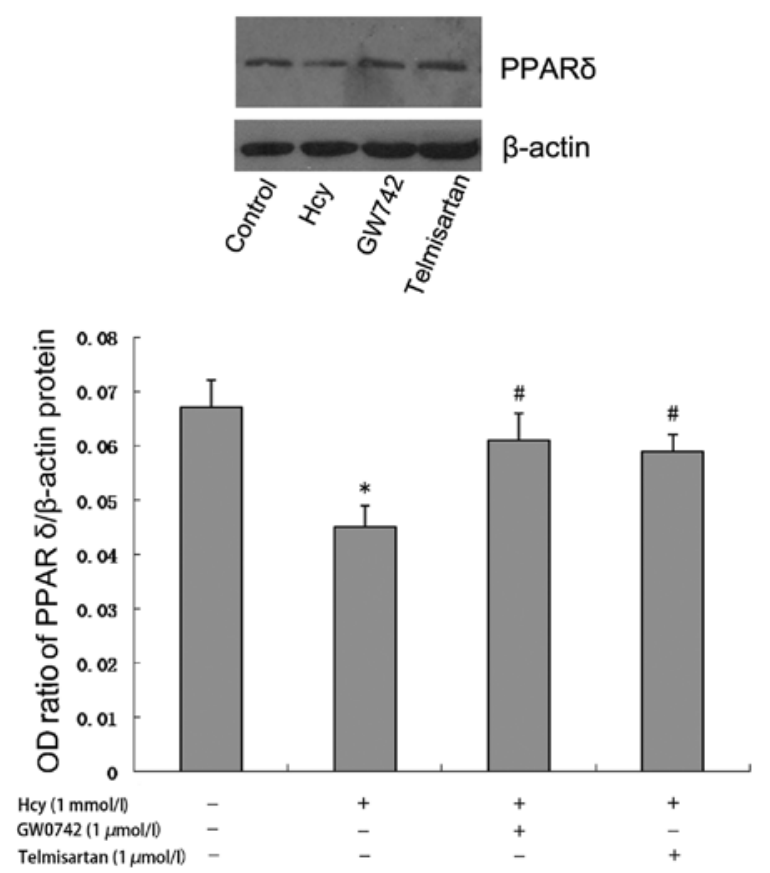

Figure 5. The effect of telmisartan on the expression of peroxisome proliferator-activated receptor- $\delta$ (PPAR $\delta$ ) protein. Western blotting was used to measure PPARס protein and expressed as the ratio of $\beta$-actin protein. Incubation with homocysteine (Hcy) significantly decreased PPARס expression. GW0742 and telmisartan significantly attenuated the effect of Hcy in human umbilical vein endothelial cells (HUVECs) $(\mathrm{n}=3)$. ${ }^{*} \mathrm{P}<0.05$ vs. control group; ${ }^{~} \mathrm{P}<0.05$ vs. Hcy group.

\section{Discussion}

Telmisartan attenuates the effect of the increased the expression of MCP-1 and VCAM-1 in HUVECs and monocyte adhesion caused by Hcy. Hyperhomocysteinemia (HHcy), which is characterized by abnormally high concentrations of homocysteine in the plasma, is associated with dysfunction of endothelium. The latter causes a chronic inflammatory reaction to cardiovascular system, eventually leading to atherosclerosis of arteries $(17,18)$. In this study, the results show that Hcy significantly increased the expression of MCP-1 and VCAM-1 in HUVECs in a concentrationdependent manner (data not shown). It is well known that an increased expression of chemokines and adhesion molecules is a critical step in inflammatory responses. Moreover, we observed that Hcy significantly increased monocyte binding to confluent HUVECs. Chemokines such as MCP-1 and adhesion molecules such as VCAM-1 play important roles in leukocyte infiltration and activation during the inflammatory processes leading to atherosclerosis $(2,3,14)$. Thus, we hypothesize that Hcy-induced MCP-1 and VCAM-1 expression in endothelial cells may participate in the process of atherosclerosis in patients with hyperhomocysteinemia. Notably, it was observed that telmisartan significantly attenuated Hcy-induced MCP-1 and VCAM-1 expression and reduced cell adherence to HUVECs in a concentration-dependent manner (data not shown). The results were consistent with previous studies that demonstrated that telmisartan pleiotropically modulates tumor necrosis factor- $\alpha$ (TNF- $\alpha$ )-induced VCAM-1 expression and oxidative damage in vascular endothelium by acting

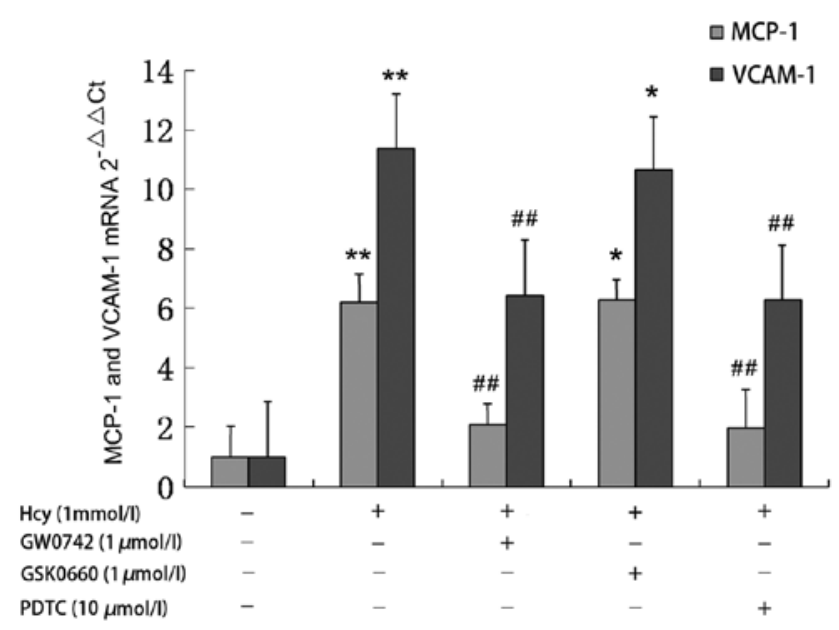

Figure 6. Effects of GW0742 [peroxisome proliferator-activated receptor- $\delta$ (PPARס) agonist], GSK0660 (PPARd antagonist) and PDTC [nuclear factor- $\kappa \mathrm{B}(\mathrm{NF}-\kappa \mathrm{B})$ inhibitor] treatment on homocysteine (Hcy)-induced monocyte chemoattractant protein-1 (MCP-1) and vascular cell adhesion molecule-1 (VCAM-1) mRNA expression in human umbilical vein endothelial cells (HUVECs). Incubation with Hcy significantly increased the mRNA expression of MCP-1 and VCAM-1. GW0742 and PDTC significantly attenuated the effect of Hcy in HUVECs, while GSK0660 had no effect $(n=5)$. ${ }^{* *} \mathrm{P}<0.01$ vs. control group; ${ }^{\# \#} \mathrm{P}<0.01$ vs. Hcy group; ${ }^{\circ} \mathrm{P}>0.05$ vs. Hcy group.

as a hydroxyl radical scavenger (19). However, whether there are other signaling pathways that are involved in the effect of inhibition of inflammation of telmisartan in endothelial cells remains to be clarified.

Telmisartan inhibits the inflammatory activity and effect of monocyte adhesion caused by Hcy via the PPAR pathway in HUVECs. PPARD is a family of nuclear receptors that plays a significant role in inflammatory processes and atherosclerosis (20-22). In recent years, understanding of the impact of PPARס in endothelial dysfunction and atherosclerosis has increased. It was observed that PPAR $\delta$ mediates resistance to atherosclerosis through upregulation of the 14-3-3 protein $\varepsilon$ in human endothelial cells (23). It was also found that telmisartan prevents adipogenesis and weight gain through the activation of PPAR $\delta$-dependent signaling pathways $(24,25)$. Thus, we hypothesized that telmisartan is involved in anti-inflammatory effects through the PPAR $\delta$ pathway. In this study, cells were preincubated with Hcy and PPAR $\delta$ antagonist GSK0660, followed by incubation with telmisartan. The results showed that the inhibitory effects of telmisartan on the inflammatory activity of Hcy were significantly attenuated by the GSK0660. Investigation of the effects of PPAR $\delta$ inhibition on the expression of MCP-1 and VCAM-1 induced by Hcy in vascular endothelial cells revealed no significant differences compared to the Hcy-treated group (Fig. 2). On the other hand, Fan et al (26) revealed that the PPAR $\delta$ agonists GW0742 suppressed TNF- $\alpha$-induced ensuing leukocyte recruitment. Similarly, results of this study have shown that PPARס agonists GW0742 or telmisartan significantly attenuated monocyte adhesion induced by Hcy, while the effect was significantly inhibited by GSK0660 (Fig. 3). The results indicate that telmisartan is important in inhibition of inflammation via PPAR $\delta$ pathway. To confirm the PPAR $\delta$ activation 


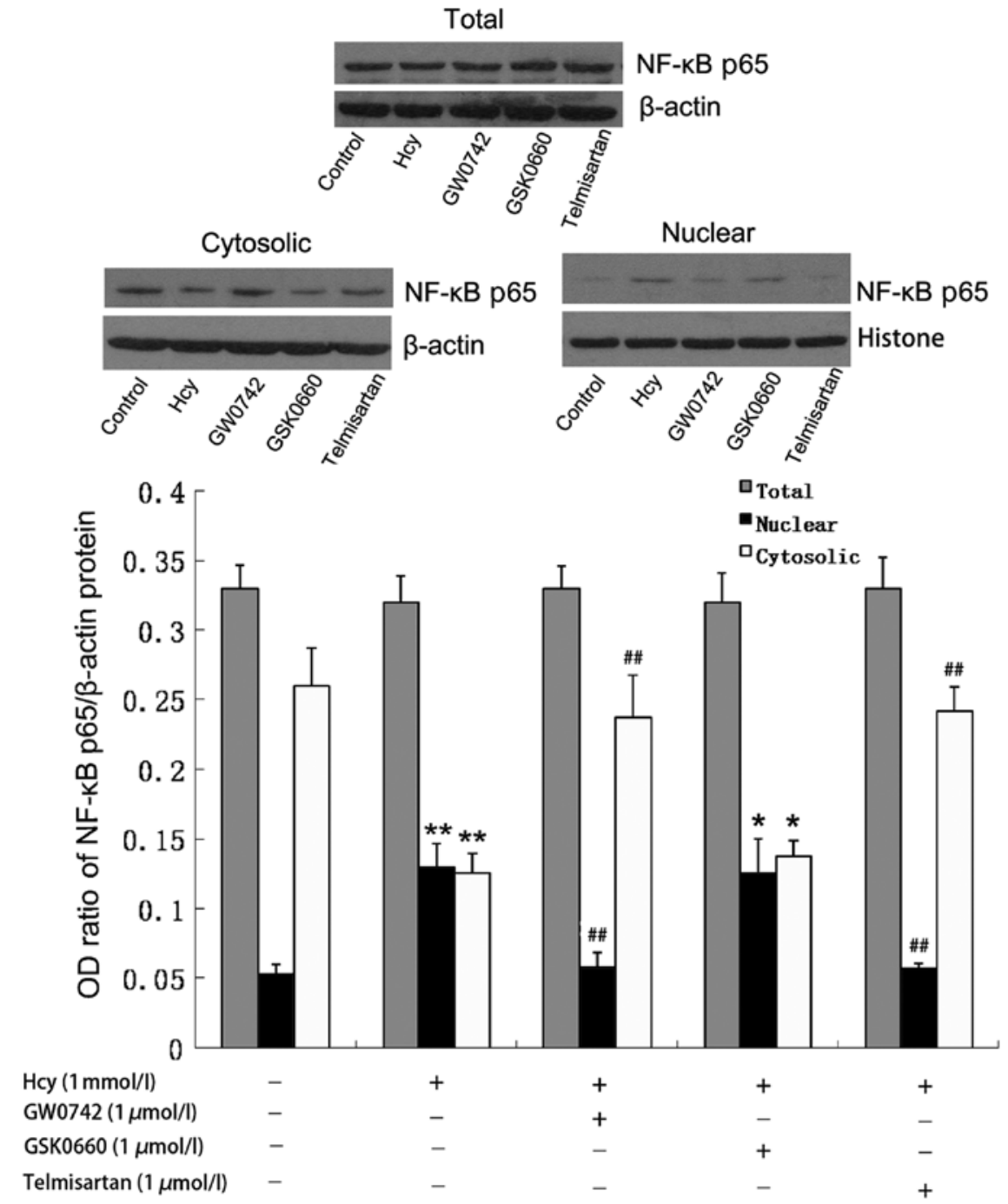

Figure 7. Effects of GW0742 [peroxisome proliferator-activated receptor- $\delta$ (PPAR $\delta$ ) agonist], GSK0660 (PPAR $\delta$ antagonist) and telmisartan on homocysteine

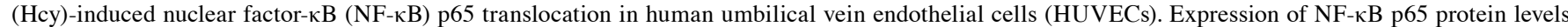
were measured as the ratio of $\beta$-actin or histone protein. Hcy increased the amount of NF- $\mathrm{kB}$ p65 in nuclear protein. Treatment with GW0742 and telmisartan significantly attenuated NF- $\mathrm{kB}$ p65 translocation in HUVECs, whereas GSK0660 had no effect $(\mathrm{n}=3)$. ${ }^{* *} \mathrm{P}<0.01$ vs. control group; ${ }^{\# \#} \mathrm{P}<0.01$ vs. Hcy group; "P>0.05 vs. Hcy group.

effect of telmisartan, we compared the impact of telmisartan and PPAR agonists on the expression of PPAR $\mathrm{mRNA}$ and protein. It was demonstrated that incubation with Hcy significantly decreased PPAR $\delta$ expression in vascular endothelium, and the effect was inhibited by telmisartan and GW0742 (Figs. 4 and 5). The results strongly suggest that telmisartan inhibits the inflammatory activity of Hcy partly via the PPAR $\delta$ pathway in vascular endothelium.

Activation of PPAR caused by telmisartan may interfere with inflammatory gene transcription via the inhibition of nuclear translocation and activation of $N F-\kappa B$. To investigate the role of PPAR $\delta$ in the proinflammatory effects of vascular endothelium cells induced by Hcy, the correlation between PPAR $\delta$ and $\mathrm{NF}-\kappa \mathrm{B}$ was investigated. In quiescent endothelial cells, NF- $\mathrm{\kappa B}$ resides in the cytoplasm in an inactive form that is associated

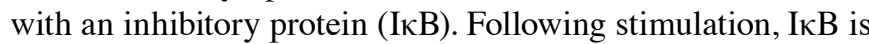
phosphorylated and degraded by the proteasome, thus allowing translocation of the dissociated NF- $\mathrm{KB}$ to the nucleus in an active form resulting in regulation of the expression of target genes including cytokines, adhesion molecules and chemokines (27). In this study, pretreatment with GW0742 and NF- $\mathrm{KB}$ inhibitor PDTC significantly attenuated the Hcy-induced MCP-1 and VCAM-1 mRNA expression, suggesting the effect of PPARS and NF- $\kappa B$ in the process of inhibition of inflammation (Fig. 6). Determination of NF- $\mathrm{kB}$ p65 levels in total, nuclear and cytosolic proteins revealed that the activation of PPARס inhibits Hcy-induced nuclear translocation of NF- $\kappa B$ in addition to inhibiting the inflammatory action of Hcy (Fig. 7). These data suggest that PPAR $\delta$ interferes with the transcription of inflammatory genes by inhibiting nuclear translocation and activation of NF- $\mathrm{KB}$ and NF- $\mathrm{KB}$ may be a downstream signaling molecule of PPAR $\delta$ in the pathway of inflammation inhibition. The above results are similar to those of a previous study, which reported that the PPAR $\delta$ agonist GW501516 inhibited the TNF- $\alpha$-mediated upregulation of mRNA levels of the NF- $\mathrm{KB}$ target gene IL-8 via decreased $\mathrm{p} 65$ acetylation in cultured human HaCaT keratinocytes in vitro (28).

In conclusion, the results of this study have demonstrated that telmisartan suppresses the Hcy-induced expression of the 
proinflammatory adhesion molecules MCP-1 and VCAM-1 in endothelial cells and attenuates the effect of monocyte adhesion. The underlying mechanism is a binary process involving the activation of PPAR $\delta$ and the prevention of the nuclear translocation of $\mathrm{NF}-\kappa \mathrm{B}$.

\section{Acknowledgements}

This study was partially supported by a grant from the Fujian Provincial Department of Science and Technology (no. 20073129). The authors gratefully acknowledge the Hypertension Institute of Fujian Province for supplying the materials used in this study and technical assistance.

\section{References}

1. Tuttolomondo A, Di Raimondo D, Pecoraro R, et al: Atherosclerosis as an inflammatory disease. Curr Pharm Des 18: 4266-4288, 2012.

2. Hulsmans M and Holvoet P: The vicious circle between oxidative stress and inflammation in atherosclerosis. J Cell Mol Med 14 70-78, 2010.

3. Oyama J, Satoh S, Suematsu N, et al: Scavenging free radicals improves endothelial dysfunction in human coronary arteries in vivo. Heart Vessels 25: 379-385, 2010.

4. Gamkrelidze M, Mamamtavrishvili N, Bejitashvili N, et al: Role of oxidative stress in pathogenesis of atherosclerosis. Georgian Med News 163: 54-57, 2008.

5. Lubos E, Handy DE and Loscalzo J: Role of oxidative stress and nitric oxide in atherothrombosis. Front Biosci 13: 5323-5344, 2008.

6. Ruilope LM: Telmisartan for the management of patients at high cardiovascular risk. Curr Med Res Opin 27: 1673-1682, 2011.

7. Kurtz TW: Treating the metabolic syndrome: telmisartan as a peroxisome proliferator-activated receptor-gamma activator. Acta Diabetol 42 (Suppl 1): S9-S16, 2005.

8. Benson SC, Pershadsingh HA, Ho CI, et al: Identification of telmisartan as a unique angiotensin II receptor antagonist with selective PPARgamma-modulating activity. Hypertension 43: 993-1002, 2004.

9. Yamagishi S, Matsui T, Nakamura K, et al: Telmisartan inhibits advanced glycation end products (AGEs)-elicited endothelial cell injury by suppressing AGE receptor (RAGE) expression via peroxisome proliferator-activated receptor-gammaactivation. Protein Pept Lett 15: 850-853, 2008.

10. Chaggar PS, Shaw SM and Williams SG: Review article: Thiazolidinediones and heart failure. Diab Vasc Dis Res 6: 146-152, 2009.

11. Panchapakesan U, Pollock C and Saad S: Review article: importance of the kidney proximal tubular cells in thiazolidinedione-mediated sodium and water uptake. Nephrology (Carlton) 14: 298-301, 2009.

12. Bishop-Bailey D and Bystrom J: Emerging roles of peroxisome proliferator-activated receptor-beta/delta in inflammation. Pharmacol Ther 124: 141-150, 2009.
13. Kilgore KS and Billin AN: PPARbeta/delta ligands as modulators of the inflammatory response. Curr Opin Investig Drugs 9: 463-469, 2008

14. Fernández-Fernández FJ: Telmisartan and obesity. Intern Med 49: 2191; author reply 2193, 2010.

15. Mauro A, Buscemi M and Gerbino A: Immunohistochemical and transcriptional expression of matrix metalloproteinases in full-term human umbilical cord and human umbilical vein endothelial cells. J Mol Histol 41: 367-377, 2010.

16. Tumur Z, Shimizu H, Enomoto A, et al: Indoxyl sulfate upregulates expression of ICAM-1 and MCP-1 by oxidative stress-induced NF-kappaB activation. Am J Nephrol 31: 435-441, 2010.

17. Woo CW, Siow YL and Karmin O: Homocysteine induces monocyte chemoattractant protein-1 expression in hepatocytes mediated via activator protein-1 activation. J Biol Chem 283: 1282-1292, 2008.

18. Dai J, Wang X, Feng J, et al: Regulatory role of thioredoxin in homocysteine-induced monocyte chemoattractant protein-1 secretion in monocytes/macrophages. FEBS Lett 582: 3893-3898, 2008.

19. Cianchetti S, Del Fiorentino A, Colognato R, et al: Antiinflammatory and anti-oxidant properties of telmisartan in cultured human umbilical vein endothelial cells. Atherosclerosis 198: 22-28, 2008.

20. Oyekan A: PPARs and their effects on the cardiovascular system. Clin Exp Hypertens 33: 287-293, 2011.

21. Wang N: PPAR-delta in vascular pathophysiology. PPAR Res 2008: 164163, 2008

22. van Bilsen M and van Nieuwenhoven FA: PPARs as therapeutic targets in cardiovascular disease. Expert Opin Ther Targets 14: 1029-1045, 2010.

23. Brunelli L, Cieslik KA, Alcorn JL, et al: Peroxisome proliferator-activated receptor-delta upregulates 14-3-3 epsilon in human endothelial cells via CCAAT/enhancer binding protein-beta. Circ Res 100: e59-e71, 2007.

24. He H, Yang D, Ma L, et al: Telmisartan prevents weight gain and obesity through activation of peroxisome proliferator-activated receptor-delta-dependent pathways. Hypertension 55: 869-879, 2010.

25. Feng X, Luo Z, Ma L, et al: Angiotensin II receptor blocker telmisartan enhances running endurance of skeletal muscle through activation of the PPAR-ס/AMPK pathway. J Cell Mol Med 15: 1572-1581, 2011.

26. Fan Y, Wang Y, Tang Z, et al: Suppression of pro-inflammatory adhesion molecules by PPAR-delta in human vascular endothelial cells. Arterioscler Thromb Vasc Biol 28: 315-321, 2008.

27. Hwang SY, Woo CW, Au-Yeung KK, et al: Homocysteine stimulates monocyte chemoattractant protein-1 expression in the kidney via nuclear factor-kappaB activation. Am J Physiol Renal Physiol 294: F236-F244, 2008.

28. Barroso E, Eyre E, Palomer X and Vázquez-Carrera M: The peroxisome proliferator-activated receptor $\beta / \delta(P P A R \beta / \delta)$ agonist GW501516 prevents TNF- $\alpha$-induced NF- $\kappa B$ activation in human $\mathrm{HaCaT}$ cells by reducing p65 acetylation through AMPK and SIRT1. Biochem Pharmacol 81: 534-543, 2011. 